\title{
SRATEGI KEPALA SEKOLAH DI DAERAH PEDESAAAN UNTUK MENINGKATKAN MUTU PENDIDIKAN DAN KARAKTER WARGA SEKOLAHNYA
}

\author{
${ }^{1}$ Liskayani \& ${ }^{2}$ Sulastri \\ ${ }^{1}$ Guru SDN 17 Air Kumbang ${ }^{2}$ Guru SDN 12 Air Kumbang \\ e-mail: ${ }^{1}$ liskayani1983@gmail.com ${ }^{2}$ sulastridaud837@gmail.com
}

\begin{abstract}
This study aimed at determining what strategies are used by the headmaster who served in rural areas with various challenges faced to improve the quality of education and character of the citizens of the school in accordance with the goals of national education. This research was a qualitative research, where in this paper researchers see the steps and efforts made by the headmaster while facing an event that is happening. Data collection technique in this study was interview to the principal of SD Negeri 17 Air Kumbang. From the results of the research, it can be seen that the strategy done by the headmaster of SD Negeri 17 Air Kumbang to improve the quality of education and character of the students is settle in the location where he served, socialize the surrounding community about the importance of education in school-aged children, improve the qualification of teachers, improving the competence of students and graduates, improving the character of students and teachers through extracurricular activities scouting and completing facilities and infrastructure in schools.
\end{abstract}

Keywords: Citizens School's Character; Headmaster's Strategy; Rural Areas; Educational Quality

\section{PENDAHULUAN}

Menurut Undang- undang Nomor 20 Tahun 2003 tentang sistem pendidikan nasional, pendidikan adalah usaha sadar dan terencana mewujudkan suasana belajar dan proses pembelajaran agar peserta didik secara aktif mengembangkan potensi dirinya untuk memiliki kekuatan spiritual keagamaan, pengendalian diri, kepribadian, kecerdasan, akhlak mulia, serta keterampilan yang diperlukan dirinya, masyarakat, bangsa dan negara. Dari undang-undang Sistem Pendidikan Nasional ini, dapat dilihat beberapa indikator mutu pendidikan di Indonesia yakni pengembangan potensi diri, memiliki kekuatan spiritual keagamaan, mampu mengendalikan diri, memiliki kepribadian, cerdas, berakhlak mulia,dan memiliki keterampilan.

Untuk mencapai indikator mutu pendidikan tersebut, pemerintah, masyarakat dan lembaga-lembaga pendidikan atau sekolah melakukan berbagai usaha. Misalnya bagi pemerintah dengan memprogramkan wajib belajar sembilan tahun di sekolah dasar secara gratis sampai tingkat SMP dengan memberikan dana BOS bagi sekolah yang bersedia menerimnya, memprogramkan pelaksanaan kurikulum yang sesuai dengan perkembangan dan tuntutan dunia pendidikan saat ini seperti kurikulum K13 dan program sekolah sehari penuh atau fulday scool. Bagi 
masyarakat misalnya dengan memberikan dukungan pada anak- anak mereka untuk terus sekolah, seperti dengan memberikan biaya untuk pendidikan anak-anak mereka. Lembaga pendidikan atau sekolah juga berusaha untuk mencapai indikator mutu pendidikan tersebut, misalnya dengan melengkapi sarana dan prasarana untuk kegiatan pembelajaran, menggunakan guru dan tenaga pendidik yang profesional atau usaha lainnya. Sehingga beberapa lembaga pendidikan berhasil mencapainya, terutama sekolah yang ada di perkotaan.

Namun, bagi sekolah yang ada di daerah pedesaan, indikator mutu pendidikan tersebut sulit untuk dicapai. Hal ini terjadi karena di daerah pedesaan, umumnya siswa yang ada di sekolah jumlahnya sedikit, sehingga dana BOS yang diterima oleh sekolah tersebut juga sedikit. Dana yang sedikit menyebabkan sekolah kesulitan memenuhi biaya operasionalnya. Para penduduk atau masyarakat di daerah terpencil biasanya telah membiasakan anak anaknya untuk bekerja sejak usia dini,untuk membantu pekerjaan orang tuanya, sehingga banyak anak yang tidak dapat berkonsentrasi pada pelajaran di sekolahnya, atau malah sampai harus putus sekolah. Hal ini karena masyarakat atau orang tua siswa di daerah pedesaan banyak yang hidup di bawah garis kemiskinan, jangankan untuk membiayai pendidikan anak-anaknya, untuk memenuhi kebutuhan pokok sehari-hari saja kadang mereka mengalami kesulitan. Sekolah-sekolah di daerah pedesaan, biasanya memiliki sarana dan prasarana yang kurang memadai, seperti kurangnya ruang kelas,meja dan kursi belajar yang sudah mulai rusak, tidak adanya perpustakaan dan laboratorium, kamar mandi yang masih kurang dan buku-buku pelajaran yang kurang lengkap.

Padahal, seharusnya sekolah menyediakan fasilitas belajar yang memadai dan baik agar siswa merasa nyaman dalam melaksanakan proses belajar mengajar serta agar kedepannya mampu menghasilkan pribadi yang berkualitas baik mutu, mental, dan kepribadian. Selain itu kelengkapan fasilitas belajar bagi siswa juga berguna untuk melatih kemandirian siswa dalam memperoleh bahan ajar tambahan selain dari guru pengajar ataupun buku panduan yang mereka punya. Siswa juga bisa mengembangkan daya kreativitas dan inovatifnya melalui fasilitasfasilitas belajar yang terdapat di sekolah sehingga siswa mampu menjadi pribadi yang kreatif dan inovatif.

Kurangnya kesadaran masyarakat untuk menyekolahkan anaknya, kurangnya sarana dan prasarana di sekolah dan kurangnya guru profesional yang bersedia mengajar di daerah pedesaan menyebabkan mutu pendidikan di daerah pedesaan masih rendah. Hal ini diperparah dengan kurang efektif dan 
efisiennya strategi yang digunakan oleh kepala sekolah dalam memimpin penyelenggaraan pendidikan di sekolahnya

Selain itu, berdasarkan banyak pengalaman yang menyatakan bahwa fakta yang ditemukan di lapangan menunjukkan bahwa banyak para guru terutama guru yang sudah PNS dan bersertifikat yang enggan mengajar di daerah dengan beragam alasan. Hasil penelitian yang dilakukan oleh Berg (2006) menunjukkan bahwa salah satu faktor yang menyebabkan keengganan para guru untuk mengajar di daerah adalah letak sekolah yang sulit dijangkau. Banyak guru yang mengajar di sekolah negeri pada daerah pedesaan yang masih honor atau guru yang memiliki latar belakang pendidikan yang tidak linier dengan bidang yang mereka ajarkan di sekolah, misalkan guru hanya lulusan SMA atau lulusan MA yang mengajar pendidikan agama.

Berbeda dengan di suatu sekolah dasar, yaitu SDN 17 Air Kumbang, yang teretak di Desa Kumbang Padang Permata kecamatan Air Kumbang, Kabupaten Banyuasin Provinsi Sumatera Selatan. SDN 17 Air Kumbang dipimpin oleh Bapak Kaswanto, S.Pd. Walaupun sekolah ini berada di daerah pedesaan, namun mutu pendidikan dan karakter siswa di sekolah ini sudah cukup baik. Beberapa siswa lulusannya dapat diterima untuk melanjutkan ke sekolah negeri yang ada di ibukota provinsi. Beberapa siswa lulusan sekolah ini juga diterima untuk melanjutkan pendidikan di pondok pesantren yang bertaraf nasional. Pada UKG tahun 2015, dua orang guru dari sekolah ini, yaitu Kursih, S.Pd dan Liskayani S.Pd, mendapat nilai UKG yang tinggi hingga menjadi Instruktur Nasional untuk program Guru Pembelajar pada tahun 2016.

Pada tahun 2015, Dedah Hayati, S.Pd, salah satu guru di sekolah ini, menjadi guru berdedikasi untuk tingkat kecamatan Air Kumbang. Tahun 2017, Kursih, S.Pd menjadi instruktur pendampingan pelaksanaan K13 untuk kelas I dan kelas IV di kecamatan Air Kumbang. Dalam acara KMD (Kursus Mahir Dasar) kepramukaan yang dilaksanakan oleh Kecamatan Air Kumbang, peserta terbaik ketiga dan keempat berasal dari guru SDN 17 Air Kumbang, Dedah Hayati,S.Pd untuk terbaik ketiga dan Liskayani, S.Pd untuk terbaik keempat. Dalam lomba guru berdedikasi dan berprestasi untuk tingkat Kecamatan Air Kumbang, yang meraih juara kedua dan ketiga adalah guru dari SDN 17 Air Kumbang, yaitu Kursih, S.Pd dan Liskayani, S.Pd. Mengingat sekolah ini berada di daerah pedesaan, dengan segala keterbatasannya, maka prestasi ini bukanlah hal yang mudah untuk dicapai. Salah satu penyebab tercapainya prestasi sekolah ini karena strategi yang digunakan oleh kepala sekolahnya dalam 
usaha meningkatkan mutu pendidikan karakter warga sekolahnya. Karena peran kepala sekolah sangat menentukan sekali akan tercapainya tujuan pendidikan yang diharapkan. Rosyadi (2015:125) menyatakan bahwa peran kepala sekolah sangat berpengaruh terhadap pertumbuhan dan perkembangan pendidikan dalam meningkatkan mutu sumber daya manusia.

Menurut Whatley (2011) kepala sekolah harus mampu build costructive initiatives in hair school, selain itu, kepala sekolah juga harus kreatif karena creativity was found to be the most important factor in ensuring the success of headmaster. Oleh karena itu, strategi kepala sekolah di derah pedesaan unntuk meningkatkan mutu pendidikan dan karakter warga sekolahnya perlu dikaji.

\section{METODE PENELITIAN}

Jenis penelitian ini merupakan penelitian kualitatif, di mana pada tulisan ini peneliti melihat langkah dan upaya yang dilakukan dalam menghadapi sebuah peristiwa yang sedang terjadi. Mulyana (2008:145) menyatakan bahwa penelitian kualitatif mempunyai keunggulan lebih mudah apabila dihadapkan dengan kegiatan ganda, lebih akurat apabila disajikan secara langsung pada hakikat hubungan peneliti dan responden dan lebih dapat menyesuaikan dengan banyak pengaruh terhadap pola-pola nilai yang dihadapi. Metode kualitatif bertolak dari pandangan fenomenologis, yang mana peneliti berusaha memahami arti peristiwa dan kaitankaitannya terhadap orang-orang biasa dalam situasi-situasi tertentu (Patilima, 2011) (Emzir, 2011) (Bungin, 2008) (Moleong, 2002) (Patton, 1990) (Sugiyono, 2005) (Kristiawan \& Tobari, 2017). Kristiawan \& Tobari (2017) menjelaskan bahwa pendekatan kualitatif merupakan descriptive; concerned with process rather than simply with outcomes or product; qualitative research tend the analyze their data inductively; and "meaning" is the essential concern to the qualitative approach.

Ahimsa (2012: 273) mengemukakan bahwa fenomenologi dapat diartikan sebagai ilmu pengetahuan tentang gambaran apa yang dilihat oleh seseorang, apa yang dirasakan dan diketahuinya dalam immedate awareness and axperience-nya. Penelitian ini ditujukan untuk mengimpestigasi hal-hal yang dilakukan oleh sebuah lembaga pendidikan dalam upaya menghadapi fenomena yang dihadapi.

Metode pengumpulan data yang digunakan dalam penelitian ini adalah wawancara langsung dengan narasumbernya yaitu kepala SDN 17 Air Kumbang, Bapak Kaswanto, S.Pd. Peneliti melakukan teknik wawancara dengan mengajukan pertanyaan pertanyaan untuk memperoleh informasi yang berkaitan dengan strategi yang digunakan oleh kepala SDN 17 Air Kumbang untuk 
meningkatkan mutu pendidikan dan karakter warga sekolahnya.

Di samping itu peneliti juga mengemukakan data dari dokumen yang peneliti dapatkan di sekolah tempat bertugasnya kepala sekolah yang diteliti. Teknik analisis data yang digunakan dalam penelitian ini adalah analisis data kualitatif yang mengikuti konsep yang diberikan oleh Miles dan Huberman (1992) dengan merealisasikan komponen pokok meliputi "pengumpulan data, reduksi data, penyajian data,dan penarikan kesimpulan.”

Proses analisis data diawali dengan pengumpulan data. Selanjutnya setelah data dikumpulkan, data tersebut direduksi. Reduksi data merupakan proses seleksi, pemfokusan dan penyederhanaan dan abstraksi data yang ada. Proses reduksi data berlangsung terus menerus sepanjang penelitian. Setelah data dipilah-pilah, selanjutnya data disajikan alam bentuk kalimat yang disusun secara logis dan sistematis mengacu pada rumusan masalah. Pada tahap akhir adalah mengambil kesimpulan atau verifikasi data. Kegiatan dalam tahap akhir adalah mengambil kesimpulan atas pola-pola atau konfigurasi tertentu. Hasil kesimpulan perlu diverifikasi ulang agar dapat mengembangkan ketelitian hasil penelitian.

\section{HASIL PENELITIAN DAN \\ PEMBAHASAN}

Berdasarkan hasil wawancara langsung dengan kepala SDN 17 Air Kumbang, Bpk Kaswanto, S.Pd, pada tanggal20 November 2017, strategi yang dilakukan untuk meningkatkan mutu pendidikan dan karakter warga di sekolahnya adalah dengan menetap di tempat ia bertugas, mensosialisasikan pada masyarakat sekitar tentang pentingnya pendidikan, meningkatkan kompetensi dan kualifikasi guru, meningkatkan kompetensi siswa dan mutu lulusan, meningkatkan karakter warga sekolah dengan kegiatan kepramukaan, melengkapi sarana dan prasarana sekolah secara bertahap.

1. Kepala sekolah menetap di tempat ia bertugas.

Agar dapat melaksanakan tugas dengan semaksimal mungkin, kepala sekolah bersedia menetap di desa tempat ia bertugas. Dengan menetap, kepala sekolah akan dapat meluangkan waktu yang lebih banyak untuk mengurus sekolahnya. Kepala sekolah akan lebih mengenal situasi dan kondisi di sekolahnya. Ia akan datang lebih tepat waktu, lebih mengenal guru guru, tenaga pendidik, para siswa dan para orang tua siswa yang ada di sekolahnya. Dengan mengenal lingkungan interen dan eksteren sekolahnya dengan baik, kepala sekolah akan dapat memberikan keputusan dengan lebih bijaksana dan sesuai dengan kebutuhan warga sekolahnya. 
2. Kepala sekolah aktif bersosialisasi dengan masyarakat sekitar sekolah.

Dengan aktif bersosialisasi dengan masyarakat, kepala sekolah akan lebih diterima oleh masyarakat. Sehingga kepala sekolah akan lebih mudah untuk mendapatkan dukungan dari masyarakat untuk dapat menigkatkan mutu pendidikan. Dalam setiap kesempatan kepala sekolah dapat menyampaikan pada masyarakat bahwa pendidikan itu sangat penting untuk putra putri mereka. Jangan sampai putra putri mereka dituntut untuk membantu orang tuanya bekerja atau untuk mengasuh adik, sehingga mereka tidak dapat fokus pada sekolahnya atau malah sampai harus putus sekolah. Apalagi untuk anak putri, biasanya pada usia sekolah sudah ada yang dinikahkan untuk mengurangi beban ekonomi keluarga.

3. Meningkatkan kompetensi dan kualifikasi guru

Menurut PP No. 19 Tahun 2005 tentang Standar Nasional Pendidikan disebutkan bahwa pendidik harus memiliki kualifikasi akademik dan kompetensi sebagai agen pembelajaran, sehat jasmani dan rohani, serta memiliki kemampuan untuk mewujudkan tujuan pendidikan nasional. Lebih lanjut diperjelas maksud dari kualifikasi akademik bagi seorang guru, yaitu tingkat pendidikan minimal yang harus dipenuhi seorang pendidik dibuktikan dengan ijazah dan/ sertifikat keahlian yang relevan sesuai ketentuan perundang-undangan yang berlaku.

Guru pada jenjang Pendidikan Anak Usia Dini (PAUD) sampai dengan SLTA berdasarkan Pasal 29 Peraturan Pemerintah (PP) No.19 Tahun 2005 persyaratan pendidik meliputi : (1) kualifikasi akademik minimum diploma empat (D-IV) atau sarjana (S1); (2) latar belakang pendidikan tinggi sesuai dengan bidang pengajarannya;(3) memiliki sertifikat sebagai pendidik.

Usaha yang dilakukan oleh kepala SDN 17 Air Kumbang untuk meningkatkan kompetensi dan kualifikasi guru di sekolahnya adalah dengan memberikan dukungan dan bantuan secara materi walaupun ala kadarnya pada guru dan tenaga pendidik untuk meningkatkan kualifikasi akademiknya. Misalnya bagi guru dan tenaga pendidik yang hanya lulusan SMA untuk melanjutkan ke jenjang $S$ melalui Universitas Terbuka. Sehingga guru dan tenaga pendidik tersebut dapat meningkatkan kualifikasi akademiknya tanpa harus mengganggu tugasnya di sekolah. Bagi guru dan tenaga pendidik yang sudah menyelesaikan S1, diberi dukungan untuk melanjutkan pendidikan ke jejang S2. Selain itu, setiap ada diklat dan pelatihan untuk meningkatkan kualifikasi guru dan tenaga pendidik, kepala sekolah akan selalu mengirim perwakilan dari sekolahnya untuk mengikuti 
kegiatan tersebut. Kemudian mereka diminta untuk menyampaikan apa yang telah didapatkan dari pelatihan pada rekan - rekan di sekolahnya. Misalnya saja pelatihan penulisan karya ilmiah atau pelatihan penerapan kurikulum K 13.

Ketika akan mengangkat guru atau tenaga pendidik honor, selain memperhatikan kualifikasinya kepala sekolah akan lebih mengutamakan mengangkat guru atau tenaga pendidik yang menetap atau jarak rumahnya tidak terlalu jauh dari sekolah. Ha ini bertujuan agar guru atau tenaga pendidik tersebut dapat lebih aktif,dapat lebih disiplin hadir ke sekolah tepat waktu.

Apabila ada guru PNS dari luar desa yang ditugaskan di sekolahnya, maka kepala sekolah akan menerimanya dengan memberikan berbagai kemudahan. Kepala sekolah akan bertindak sebagai orang tua agar guru PNS yang baru merasa betah menetap di desa tempat sekolahnya. Misalnya dengan memberikan bantuan tempat tinggal atau dengan memberikan bimbingan agar sang guru membeli lahan perkebunan untuk mendapatkan penghasilan tambahan di desanya tersebut.

Usaha lain yang dilakukan oleh kepala sekolah untuk meningkatkan kualitas guru dan tenaga pendidik adalah dengan mengajak para guru dan tenaga pendidik untuk belajar menggunakan komputer bagi yang belum bisa. Biaya yang diperlukan untuk belajar komputer ini ditanggung oleh sekolah. Sehingga pada setiap hari sabtu setelah jam pelajaran berakhir, para guru dan tenaga pendidik belum dulu pulang ke rumah masing-masing, tetapi mereka berkumpul di suatu ruangan untuk belajar menggunakan komputer.

4. Meningkatkan kompetensi siswa dan mutu lulusan

Kompetensi siswa dan mutu lulusan merupakan tujuan utama sebuah lembaga pendidikan. Semua usaha yang dilakukan ditujukan untuk meningkatkan kompetensi siswa dan mutu lulusan. Baik beruknya mutu sebuah lembaga pendidikan dapat dilihat dari mutu siswa dan lulusannya. Apalah artinya kepala sekolah,guru dan tenaga pendidik yang profesional, sarana dan prasarana yang lengkap jika mutu siswa dan lulusannya tidaklah baik.

\section{SDN 17 Air Kumbang merupakan} satu-satuya sekolah dasar yang ada di desa KP.Permata, Kecamatan Air Kumbang. Oleh karena itu sekolah ini menerima seluruh calon siswa yang mendaftar di sekolah ini baik siswa yang biasa maupun yang menyandang keluarbiasaan. Agar tidak ada siswa di desa ini yang putus sekolah. Walaupun kemampuan siswa di sekolah ini beragam, kepala sekolah dan guru berusaha meningkatkan kompetensi siswa dan mengembangkan kemampuan siswa 
sesuai dengan bakatnya masing-masing. Misalnya siswa yang berbakat di bidang olah raga akan diasah bakatnya dengan melatihnya di bidang olah raga dan mengirimnya untuk mengikuti lomba- lomba cabang olah raga, baik ditingkat kecamatan ataupun kabupaten.

Untuk meningkatkan kompetensi siswa pihak sekolah juga mengadakan pelajaran tambahan bagi siswa-siswanya, yaitu dengan mgadakan pelajaran tambahan komputer, bahasa inggris, matematika dan pramuka. Apabila ada peringatan hari- hari besar nasional ataupun keagamaan, sekolah akan mengadakan lomba-lomba untuk mengasah kemampuan anak. Misalnya pada peringatan hari Pendidikan Nasional atau HUT RI, sekolah akan mengadakan lomba cepat tepat, lomba mengarang, lomba baca puisi dan lomba lainnya. Atau pada peringatan Hari Besar Keagamaan seperti peringatan Maulid Nabi Muhammad akan diadakan lomba-lomba keagamaan, misalnya lomba azan, lomba baca Qur'an, lomba menghapal ayat ayat pendek, lomba praktek sholat. Dapat dikatakan bahwa sekolah ini mengikuti aliran pendidikan progresivisme dan filsafat keagamaan.

Semua kegiatan- kegiatan ini dilaksanakan dengan tujuan agar para siswa dan lulusan dari sekolah ini dapat berprestasi dan berkompetensi dengan siswa-siswa dari sekolah lain, termasuk siswa dari sekolah yang ada di perkotaan. Para siswa dan lulusannya bukan hanya mampu berkompetensi di bidang akademik tetapi juga dari segi sikap dan akhlakya, sehingga tujuan pendidikan nasional akan dapat tercapai.

5. Meningkatkan karakter warga sekolah melalui kegiatan ekstrakurikuler kepramukaan.

Menurut Kristiawan (2016), pendidikan karakter anak usia Sekolah Dasar sangat efektif dilakukan di sekolah. Lingkungan sekolah (guru dan siswa) memiliki peran yang kuat dalam membentuk karakter anak. Renata dkk (2017) menyebutkan bahwa pendidikan karakter dapat dimaknai sebagai "the deliberate use of all dimensions of school life to foster optimal character development".

Pendidikan karakter merupakan bentuk kegiatan manusia yang di dalamnya terdapat suatu tindakan yang mendidik dan diperuntukkan bagi generasi selanjutnya (Wulandari \& Kristiawan, 2017). Hasil temuan Ahmad dkk (2017) mengungkapkan bahwa implementasi pembelajaran karakter adalah (1) menerapkan metode pembelajaran yang melibatkan partisipatif aktif siswa, (2) menciptakan lingkungan belajar yang kondusif, (3) memberikan pembelajaran karakter secara eksplisit, sistematis, dan berkesinambungan dengan melibatkan aspek knowing the good, loving the good, and acting the good, dan (4) memperhatikan keunikan 
siswa masing-masing dalam menggunakan metode pembelajaran.

Pendidikan karakter di sekolah untuk para siswa dapat dilaksanakan pada semua pelajaran dan kegiatan di sekolah. Termasuk kegiatan ekstrakurikuler kepramukaan. Dalam kegiatan kepramukaan, siswa dididik dan dilatih dengan berbagai pendidikan karakter yang terdiri dari olah hati, olah rasa, olah karsa dan olah raga. seperti karakter relijius, disiplin, jujur, peduli, sopan, terampil, mandiri, cerdas dan produktif. A person's success is not determined solely by the knowledge and technical skills (hard skills), but rather by the ability to manage themselves and others (soft skills) (Kristiawan, 2015).

Pendidikan dan pelatihan dalam kegiatan kepramukaan akan memberikan pengalaman bagi siswa hingga mereka dapat berkarakter lebih baik, seperti yang dinyatakan oleh Kristiwan (2016) bahwa banyak pengalaman orang-orang yang berkarakter negatif dapat berubah menjadi positif setelah mereka dihadapkan pada permasalahan hidup dan belajar dari kehidupan orang lain yang sedang mengalami masalah.

Untuk kegiatan kepramukaan di SDN 17 Air Kumbang dilaksanakan setiap hari Jumat pukul 14.00 WIB, dengan melibatkan kepala sekolah dan seluruh guru sebagai pembinanya. Kepala sekolah dan guru di SDN 17 Air Kumbang dapat menjadi pembina pramuka di Gugus Depannya karena pada tanggal 5-10 November 2017, Kepala SDN17 Air Kumbang bersama 7 orang guru di SDN 17 Air Kumbang pada tanggal 5-10 November 2017 mengikuti KMD (Kursus Mahir Dasar) kepramukaan yang dilaksanakan di SND 3 Air Kumbang. Apabila seorang guru telah mendapat sertifikat lulus mengikuti KMD, maka ia telah mendapatkan "SIM" untuk dapat menjadi seorang pembina pramuka di sekolah atau gugus depannya. 
JMKSP

(Jurnal Manajemen, Kepemimpinan, dan Supervisi Pendidikan)

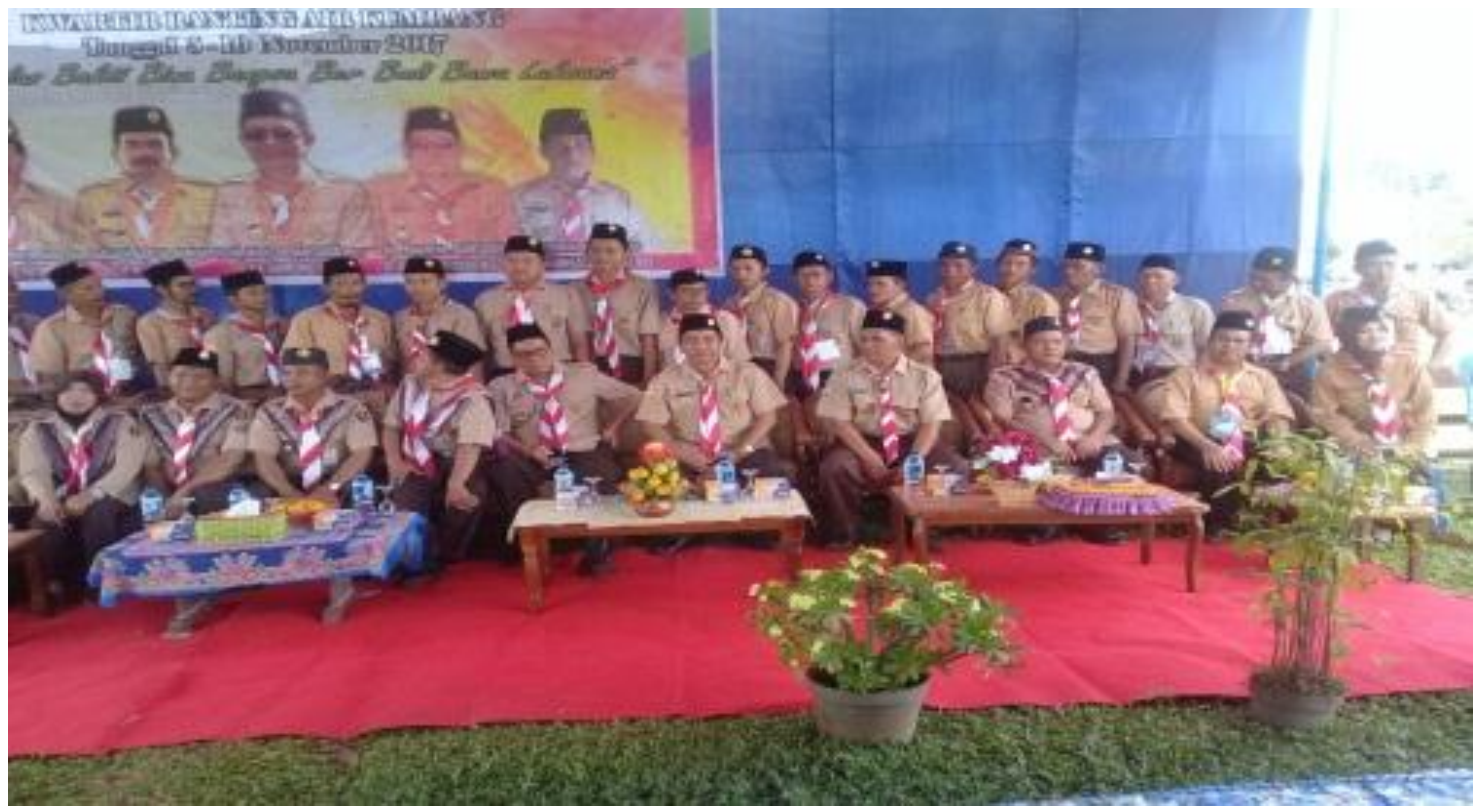

Gambar 1. Kepala SDN 17 Air Kumbang mengikuti KMD

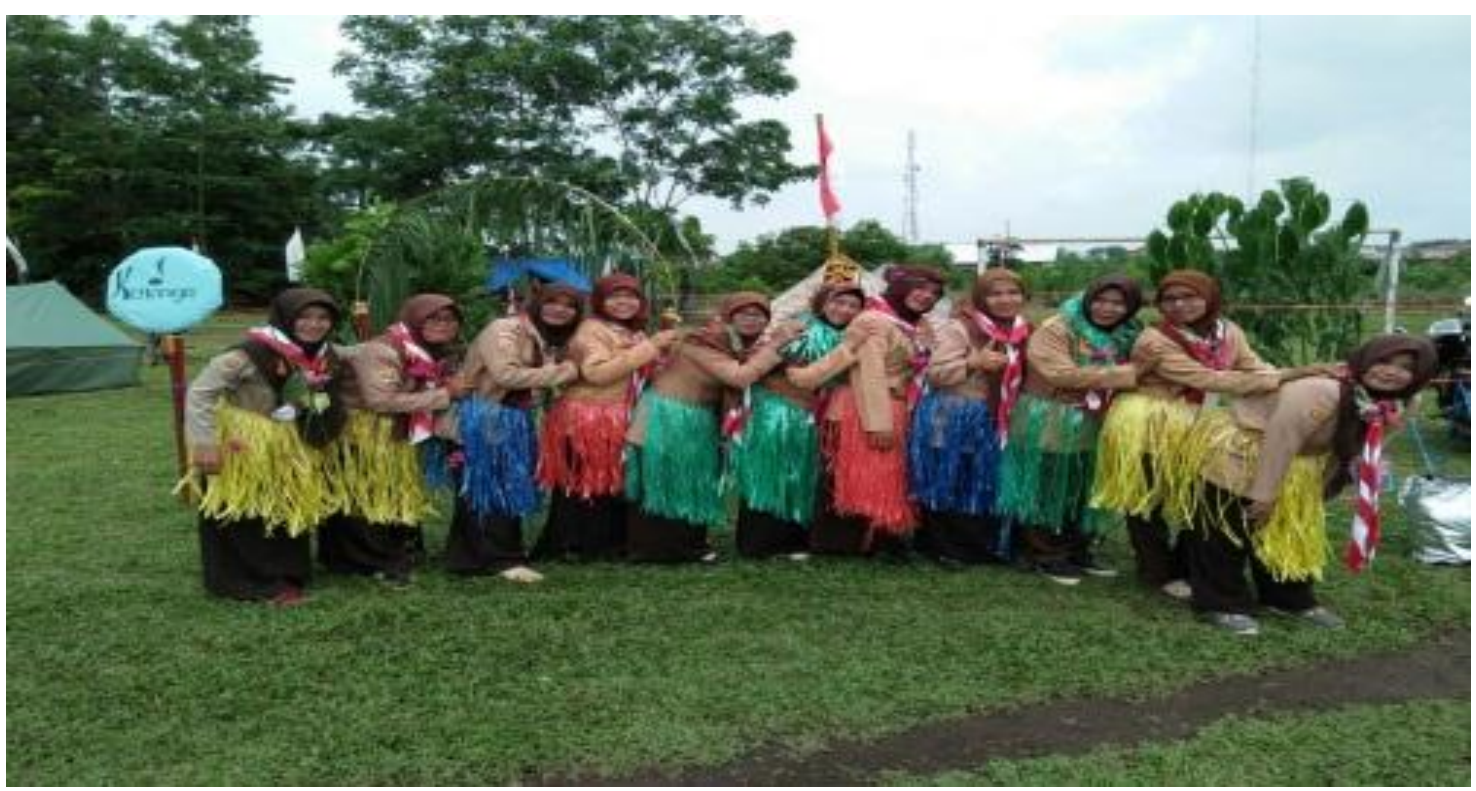

Gambar 2. Guru SDN 17 Air Kumbang mengikuti KMD 


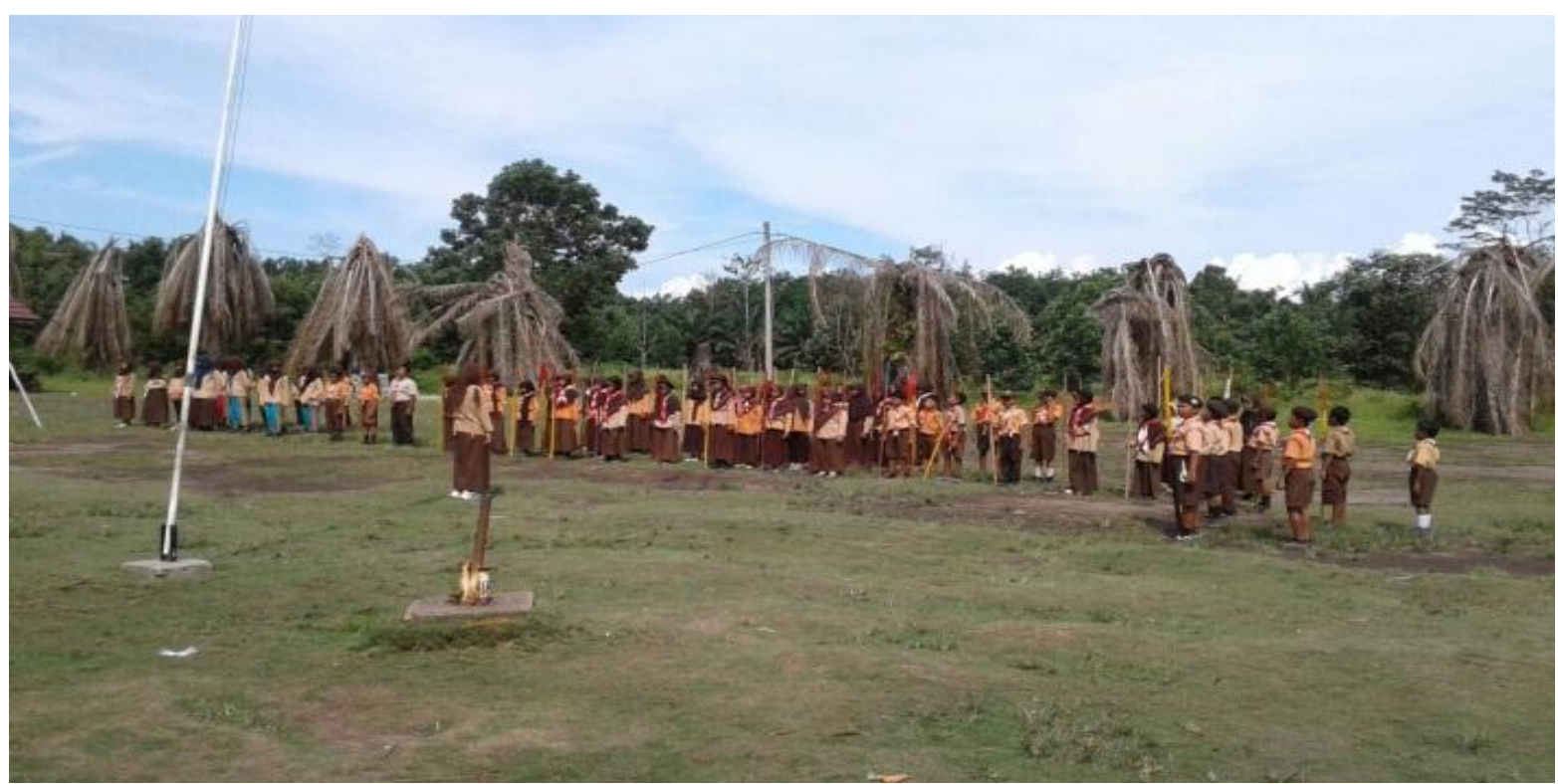

Gambar 3. pelaksanaan kegiatan kepramukaan di SDN 17 Air Kumbang

6. Melengkapi sarana dan prasarana secara bertahap

Ketersediaan sarana dan prasarana yang lengkap merupakan salah satu faktor yang menentukan mutu dan kualitas pendidikan. Dengan sarana dan prasarana yang lebih memadai siswa akan dapat belajar dengan baik. Untuk itu, kepala sekolah perlu mengusahakan ketersediaan dan kesiapan sarana dan prasarana sekolah seperti ruang kelas, perpustakaan, meja, kursi,lemari tempat penyimpanan buku dan sebagainya. Kemudian kepala sekolah perlu mengelolah program perawatan preventif, pemeliharaan dan perbaikan sarana dan prasarana.

Untuk melengkapi dan memelihara sarana dan prasarana yang ada di sekolahnya, kepala SDN 17 Air Kumbang harus bekerja keras. Mengingat terbatasnya dana yang diterima oleh sekolah ini. Terbatasnya jumlah dana yang diterima oleh sekolah karena sedikitnya jumlah siswa yaitu hanya 218 orang pada tahun pelajaran 2017/2018. Padahal jumlah siswa pada tahun ini dapat dikatakan lebih banyak jika dibandingkan beberapa tahun sebelumnya.

Apabila ada waktu luang baik saat jam pelajaran atau diluar jam pelajaran di sekolah, kepala sekolah akan membuat dan memperbaiki sendiri sarana dan prasarana yang kurang, misalnya membuat lemari untuk tempat penyimpanan buku, memperbaiki sendiri meja dan kursi yang mulai rusak, mengecat sendiri diding kelas yang mulai pudar, membuat sendiri sumur untuk sumber air kamar mandi sekolah, merapikan rumput yang tumbuh di halaman sekolah,menimbun tempat-tempat yang becek di sekitar sekolah dan lain sebagainya. 


\section{KESIMPULAN DAN SARAN}

Keanekaragaman kegiatan yang dilakukan disekolah memberikan pengetahuan dan pengalaman bagi warga sekolah, sehingga akan menghasilkan prestasi. Prestasi merupakan bukti dari mutu sebuah sekolah dan tingkat karakter warga sekolahnya.

Berdasarkan penelitian ini, dapat disimpulkan bahwa strategi yang dilakukan oleh kepala sekolah SD Negeri 17 Air Kumbang Kecamatan Air Kumbang Kabupaten Banyuasin untuk meningkatkan mutu pendidikan di sekolahnya adalah dengan menetap di lokasi tempat ia bertugas, mensosialisasikan pada masyarakat sekitar sekolah betapa pentingnya pendidikan untuk anak - anak usia sekolah, meningkatkan kualifikasi guru dan tenaga pendidik, meningkatkan kompetensi siswa dan lulusan, meningkatkan kerakter warga sekolah melalui berbagai kegiatan, termasuk kegiatan ekstrakurikuler kepramukaanan dan melengkapi sarana prasarana sekolah secara bertahap.

Sebagai saran untuk kepala sekolah atau calon kepala sekolah di daerah pedesaan yang mutu pendidikan dan karakter warga sekolahnya masih rendah agar dapat menggunakan hasil penelitian ini guna meningkatkan mutu pendidikan dan kerakter warga sekolahnya.

\section{DAFTAR PUSTAKA}

Ahmad, S., Kristiawan, M., Tobari, T., \& Suhono, S. (2017). Desain Pembelajaran SMA Plus Negeri 2 Banyuasin III Berbasis Karakter Di Era Masyarakat Ekonomi ASEAN. Iqra (Educational Journal), 2(2), 403-432.

Ahimsa, Shri Heddy, Putra (2012) Fenomenologi Agama : Pendekatan Fenomenologi Untuk Memahami Agama Jurnal Walisongo Volume 20 Nomor 2.

Bungin, M. Burhan (2008). Penelitian Kualitatif, Komunikasi, Ekonomi, Kebijakan Publik dan Ilmu Sosial Lainnya. Jakarta : Kencana

Emzir. (2011). Analisis Data: Metodologi Penelitian Kualitatif. Jakarta : Rajawalai Press

Kristiawan, M. (2015). A Model of Educational Character in High School Al-Istiqamah Simpang Empat, West Pasaman, West Sumatera. Research Journal of Education, 1(2), 15-20.

Kristiawan, M. (2016). Telaah Revolusi Mental Dan Pendidikan Karakter Dalam Pembentukkan Sumber Daya Manusia Indonesia Yang Pandai dan Berakhlak Mulia. Ta'dib, 18(1), 13-25.

Kristiawan, M. (2017). The Characteristics of the Full Day School Based Elementary School. Transylvanian Review, 1(1).

Maleong, Lexy J. (2007). Metodologi Penelitian Kualitatif . Bandung : Remaja Rosdakarya

Mulyana, D. (2008). Metodologi Penelitian Komunikasi.Bandung. Remaja Rosdakarya.

Patilima, Hamid. (2011). Metode Penelitian Kualitatif. Bandung. CV Alfabeta. 
Patton, Michail Quin (1990). Qualitative Evaluation and Research Method. Newbury Park : Sage Publication.

Peraturan Pemerintah No.19 Tahun 2005 pasal 19

Rosyadi, Yogi Irfan, Pardjono. (2015). Peran Kepala Sekolah Sebagai Manajer Dalam Meningkatkan Mutu Pendidikan di SMP 1 Cilawu Garut. Jurnal Akuntabilitas Manajemen Pendidikan $V$ ol. 3 No. 1 April 2015.

Renata, R., Kristiawan, M., \& Pratami, F. A. R. (2017, December). Perbincangan Pendidikan Karakter. In Prosiding Seminar Nasional Program Pascasarjana.

Sugiyono. (2005). Memahai Penelitian Kualitatif. Bandung: Alfabeta.

Undang-undang No 20 Tahun 2003 tentang Sistem Pendidikan Nasional. Jakarta: CV Tamita Utama

Whatley, Ceri (2011). “The role of Headmasters in the seccessfull Implementation of One Laptop per Chill: A case study in Rwanda". Research Journal of World Relief Building, Kacyiru, Kigali, Rwanda 2. (10) 2011.

Wulandari, Y., \& Kristiawan, M. (2017). Strategi Sekolah dalam Penguatan Pendidikan Karakter Bagi Siswa dengan Memaksimalkan Peran Orang Tua. JMKSP (Jurnal Manajemen, Kepemimpinan, dan Supervisi Pendidikan), 2(2). 